\title{
TER ANEMIA FALCIFORME: nota prévia sobre seu significado pera a criança expresso através da brincadeira"
}

\author{
A na Augusta M aciel de SOU ZA ${ }^{b}$, Circéa A mália RIBE IROㄷ, Regina I ssuzu H iroka de BORBA d
}

\section{RESUMO}

N ota prévia de uma pesquisa que tem como objetivo compreender o significado de ter anemia falciforme para crianças de 3 a 12 anos de idade, a partir de uma investigação qual itativa ancor ada no Interacionismo Simbólico como referencial teórico, e na Teoria Fundamentada nos Dados como referencial metodológico. Os dados são coletados por meio de entrevista com as crianças, mediada por uma sessão de Brinquedo Terapêutico. A análise preliminar dos dados per mitiu compreender que ter anemia fal ciforme é uma vivência triste para a criança, porque, al ém de ser per meada pela dor, el a se percebe impotente frente ao sofrimento, reconhece seus sintomas, compreende a necessidade do tratamento, consider ando-o apenas paliativo; que a família é um importante suporte, e o hospital, uma referência.

Descritores: Jogos e brinquedos. Criança. A nemia fal ciforme. Enfermagem pediátrica.

\section{RESUMEN}

$\mathrm{N}$ ota previa de una investigación que tiene como objetivo comprender el significado de tener anemia falciforme para niños de 3 a 12 años. Investigación cualitativa anclada en el Interaccionismo Simbólico como referencia teórica y en la T eoría $F$ undamentada en los datos como referencia metodológica. L os datos son recolectados por medio de entrevista con los niños, mediada por una sesión de J uguete Terapéutico. E I análisis preliminar de los datos permitió comprender que tener anemia falciforme es una vivencia triste para el niño, porque además de ser atravesado por el dolor, él se percibe impotente frente al sufrimiento, reconoce los síntomas, comprende la necesidad de tratamiento, considerándolo solamente paliativo, que la familia es un soporte importante y el hospital una referencia.

Descriptores:] uego e implementos de juego. N iño. A nemia de células falciformes. E nfermería pediátrica. Título: T ener anemia falciforme: nota previa sobre el significado para el niño expresado a través del juego.

\section{ABSTRACT}

B rief notice of a study aimed at understanding the significance of sickle cell anemia in children between 3 and 12 years old. This qualitative research is grounded in Symbolic Interactionism as a theor etical perspective, and in G rounded Theory as a research method. The data have been collected through interviews with dildren, with the use of therapeutic play sessions. P reliminary data analysis has allow ed us to understand that sickle cell anemia is a sad experience for children, because that more than experiencing pain, children realize they are powerless in relation to the suffering; they recognize its symptoms, understand the need for treatment, and consider it only as palliative. Children also consider their family as an important support, and have the hospital as reference.

Descriptors: P lay and playthings. Child. A nemia, sickle cell. P ediatric nursing.

Title: Sickle cell disease: short communication on how children express through games what it means for them to have the disease.

\footnotetext{
a Pesquisa sendo desenvolvida junto ao Programa de Pós-G raduação em E nfermagem da U niversidade Federal de São Paulo (U N IF ESP), vinculada ao Grupo de Estudos do Brinquedo (G EBrinq).

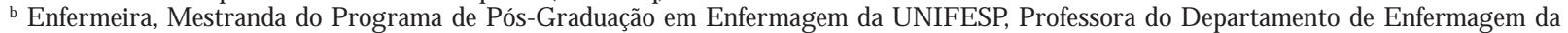

U niversidade E stadual de M ontes Claros e das F aculdades Integradas Pitágoras de M ontes Claros, M inas G erais, Brasil.

c Enfermeira, Professora A ssociada do Departamento de Enfermagem da UNIFE SP, São Paulo, Brasil.

' Enfermeira, Professora A djunta do D epartamento de Enfermagem da U NIF ESP, São Paulo, Brasil.
} 


\section{INT RODUÇÃO}

A anemia falciforme é uma hemoglobinopatia de caráter genético, hereditário, de alta morbidade e mortalidade. Caracteriza-se por anemia hemolítica crônica grave resultante de mutação e dando origem à hemoglobina $\mathrm{S}$ com características físico-químicas alteradas. Com a mutação, a hemoglobina é cristalizada, propiciando alterações morfológicas que lhe dão o formato de foice, e desencadeando vaso-oclusão, que provoca a isquemia nos tecidos ${ }^{(1,2)}$. É uma doença que não tem cura, por isso, o que deve ser instituído é um tratamento eficaz que evite condições que aumentem o fenômeno de fal cização(3).

Direcionar a investigação para a criança com anemia fal ciforme fundamenta-se pel as inter nações frequentes, pelas complicações da doença, pelo número expressivo dessa hemoglobinopatia no Brasil, considerada um problema de saúde pública(4) e pelas lacunas existentes a respeito da compreensão dessa vivência para a criança, evidenciada ao realizarmos busca na literatura de enfermagem sobre a temática.

Dentro desse contexto, propusemos centrar nosso ol har nesse objeto de estudo, tendo como indagações: Como a criança define a situação de ter anemia falciforme? De que maneira ela interage com a família, os profissionais de saúde e com a própria doença? Que emoções permeiam suas interações com a doença? Como a enfermagem pode contribuir na melhoria da qualidade de vida dessas crianças?

$\mathrm{Na}$ busca de respostas a tais questionamentos, estamos realizando esta pesquisa, com o objetivo de compreender o significado de ter anemia falciforme para crianças pré-escolares e escolares, a partir de suas manifestações em sessões de brinquedo terapêutico.

\section{MÉTODO}

Dentre das possibilidades da pesquisa qualitativa, estamos utilizando como referencial teórico o I nteracionismo Simbólico, uma per spectiva de análise das experiências humanas tendo a natureza da interação como foco principal (5); e, como referencial metodológico, a Teoria Fundamentada nos $D$ ados (G rounded T heory), que possui raízes naquel e referencial e compreende a realidade a partir do conhecimento da percepção ou "significado" que certo contexto ou objeto tem para a pessoa, sendo uma abordagem com procedimentos sistematizados, com o objetivo de desenvolver uma teoria sobre deter minado fenômeno $0^{(6,7)}$.

A pesquisa foi aprovada pelo Comitê de Ética da U niversidade F ederal de São Paulo (U N IFESP), sob o $n^{\circ}$ 0244/08, e está sendo realizada na pediatria de dois hospitais de M ontes Claros, M inas Gerais, tendo como sujeitos crianças de 3 a 12 anos de idade com anemia falciforme. A amostragem não é predeterminada, e será definida durante o processo de análise dos dados, obedecendo ao critério de saturação teórica(6).

Os dados são analisados simultaneamente à coleta, conforme preconizado pela T eoria F undamentada nos Dados, ocorrendo de forma comparativa e constante $e^{(6)}$.

As estratégias para obtenção dos dados são: a observação participante e a entrevista intermediada pel o Brinquedo T er apêutico, sendo conduzida a partir da pergunta norteadora: "Vamos brincar de uma criança com anemia falciforme?".

0 Brinquedo T erapêutico é um processo não diretivo, fundamentado na função catártica do brinquedo, que possibilita à criança expressar seus desejos, medos, e preocupações. T em como meta proporcionar ao profissional "insight" das necessidades e sentimentos da criança e favorecer 0 alívio das tensões vivenciadas por ela, assim como ser um meio de comunicação ${ }^{(8,9)}$.

\section{RESULTADOS PRELIMINARES}

A análise preliminar dos dados permitiu compreender que ter anemia falciforme é uma vivência triste para a criança, porque, além da dor, ela se percebe impotente frente ao sofrimento, reconhece seus sintomas, seu estigma familiar e compreende a necessidade do tratamento, mas o considera apenas paliativo para o alívio da dor. A família é um importante suporte; 0 hospital, uma referência para 0 enfrentamento do sofrimento; e o brincar, uma fonte de al ívio para o mesmo, conforme exemplificado nos trechos extraídos das entrevistas com as crianças:

Vamos brincar de uma criança com anemia falciforme? [ Criança olha para as bonecas e diz] Elas tá sorrindo demais, elastá sorrindo demais. E ter anemia falciforme é muito triste (C1).

E ssa doença só $D$ eus para te curar, tem quefazer o tratamento (C5). 
E la tá chorando [ ...] vou dar tramal, é pra ela parar de chorar, ela tá dormindo [ criança abraça a mãe]. A gora tem queesperar ela acordar [ ...] daqui meia hora e começa tudo de novo (C1).

Tá desidratada [ criança liga o soro na boneca e diz] a criança com anemia falciformefica desidratada esente dor (C6).

[ Criança pega um boneco, examina e diz] Agora, o papai, ele tem anemia falciforme [ ...] ele vai ter que ficar aqui alguns dias no hospital (C2).

\section{CONSIDERAÇÕES FINAIS}

Permitir à criança dramatizar, na sessão de brinquedo, o significado de ter anemia falciforme possibilita a compreensão de como ela interage com seu corpo, sua família, os profissionais de saúde, a doença e o tratamento, além de favorecer 0 alívio imposto pela doença falciforme e pelo tratamento decorrente.

Acreditamos que os resultados deste estudo poderão nortear a conduta dos enfermeiros na construção de estratégias que subsidiarão uma melhor assistência prestada a essa população infantil, eque poderão ser institucionalizadas com o intuito de diminuir o sofrimento das crianças com essa patologia. N ovos dados estão sendo coletados e analisados, com vistas a aprofundar a compreensão dessa vivência.

\section{REFERÊNCIAS}

1 Eufemia J, Christine M, M arilyn S, Judith EB, M arsha T LS. Changes in sleep, food intake, and activity levels during acute painful episodes in children with sickle cell disease. J Pediatr Nurs. 2006;21(1):23-34.

2 Zago M A, Pinto ACS. Fisiopatologia das doenças falciformes: da mutação genética à insuficiência de múltiplos órgãos. Rev Bras Hematol H emoter. 2007; 29(3):207-14.

3 H ockenberry M J, W ilson D, W inkelstein M L, editores. W ong fundamentos de enfermagem pediátrica. 7 ạ ed. Rio de Janeiro: Elsevier; 2006.

4 Diniz D, G uedes C, T rivelino A. E ducação para a genética em saúde pública: um estudo de caso sobre a anemia fal ciforme. Ciênc Saúde Coletiva [ I nternet] 2005 [ citado 2011 fev 01] ; 10(2):365-72. D isponível em: http:/ / www.scielo.br/ pdf/ csc/ v10n2/ a14v10n2.pdf.

5 Charon JM. Symbolic interactionism: an introduction, an interpretation, an integration. $5^{a}$ ed. $\mathrm{N}$ ew Jersey: Simon \& Schuster; 1995.

6 Strauss A, Corbin J. Pesquisa qualitativa: técnica e procedimentos para o desenvolvimento da teoria fundamentada. 2 a ed. Porto A legre: Artmed; 2008.

7 G laser BG. Theoretical sensivity. M ill Valley: Sociology; 1978.

8 Ribeiro CA, Borba RIH. A criança e o brinquedo no hospital. In: A Imeida FA, Sabatés A L , organizadores. Enfer magem pediátrica: a criança, 0 adol escente e sua família no hospital. São Paulo: M anole; 2008. p. 65-77.

9 Maia EBS, Ribeiro CA, Borba RIH. Brinquedo terapêutico: benefícios vivenciados por enfermeiras na prática assistencial à criança e família. Rev $\mathrm{G}$ aúcha Enferm. 2008;29(1):39-46.

\section{Endereço da autora / Dirección del autor / Author's address:}

Ana Augusta M aciel de Souza

Rua W alter L inhares F rota $M$ achado, 391, I bituruna

39401-285, M ontes Claros, M G

E-mail:anamaciel@uai.com.br
Recebido em: 15/ 09/2010

A provado em: 24/ 01/ 2011 